\title{
Lavanderia em jeans e a sustentabilidade em moda: comparativo entre processos tradicionais e ecológicos
}

Laundry in jeans and sustainability in fashion: a comparison

between traditional and ecological processes

\section{Sanara Luiz}

Instituto Federal de Santa Catarina

sanny_luiz@hotmail.com

B

\section{Anamélia Fontana Valentim}

Universidade do Sul de Santa Catarina

anameliafv@gmail.com

\section{PROJËTICA}

\section{COMO CITAR ESTE ARTIGO:}

LUIZ, Sanara; VALENTIM, Anamélia Fontana. Lavanderia em jeans e a sustentabilidade em moda: comparativo entre processos tradicionais

e ecológicos. Projética, Londrina, v. 12, n. 1, p. 297-326, 2021

DOI: 10.5433/2236-2207.2021v12n1p297

Submissão: 03-07-2019

Aceite: $16-03-2020$ 
RESUMO: Esta pesquisa, por meio da abordagem de investigação estudo de caso, tem como objeto a calça jeans. Seu objetivo principal é comparar dois processos de lavanderia em jeans aplicados a este mesmo produto, estimando os custos e recursos utilizados em cada método, que foram nomeados como tradicional e eco. Para tanto, abordamos brevemente a história do jeans, o ciclo de vida dos produtos e a sustentabilidade na moda, apresentando escolhas aplicáveis ao jeans e que contribuem para a preservação do meio ambiente.

Palavras-chave: Jeans. Design de lavanderia. Sustentabilidade. Moda.

\begin{abstract}
This research, through a case study, focuses on the jeans. The main objective is to compare two laundry processes in jeans applied to the same product, estimating costs and resources used in each method, referred to as traditional and eco. To this end, we briefly address the jeans history, the life cycle of products and sustainability in fashion, presenting choices that are applicable to jeans and that contribute to the environmental preservation.
\end{abstract}

Keywords: Jeans. Laundry design. Sustainability. Fashion.

\title{
1 INTRODUÇÃO
}

O jeans ficou conhecido a partir do século XIX, quando Levi Strauss passou a utilizar um tecido grosso que tinha em sua bagagem para confeccionar roupas para que os garimpeiros pudessem trabalhar nas minas americanas, pois eles precisavam de um tecido forte e resistente. Foi aí que Strauss, utilizando o molde de uma calça de um marinheiro genovês, criou a primeira calça jeans, em 1850. 
O denim passou a ser um tecido conhecido mundialmente. Com o tempo, deixou de ser relacionado apenas a trabalhadores, e passou a ser usado pelos grandes astros do cinema e da música, provocando uma das principais revoluções no modo de se vestir. Como não sofreu muitas modificações, logo tornou-se um clássico. Mesmo com ressalvas, jovens no mundo todo usavam jeans, impulsionando sua associação também ao lazer ao manifestarem socialmente seu potencial múltiplo.

Com a aceitação e o crescimento do jeans, as indústrias têxteis começaram a desenvolver novos processos de beneficiamento para os tecidos e itens feitos a partir dele. Surgem assim as lavanderias industriais, que são responsáveis pelas inúmeras lavagens, dando ao produto características que aumentam seu valor agregado. O jeans tornou-se um verdadeiro ícone de moda, um item indispensável no guarda-roupa de muitas pessoas.

Partindo deste entendimento inicial, optou-se pela calça jeans como objeto de estudo desta pesquisa, que tem como objetivo principal comparar dois processos de lavanderia aplicados a um mesmo produto. Os dados comparativos obtidos foram utilizados para estimar custos e recursos de cada método, além de demonstrar visualmente o resultado dos processos nas duas calças confeccionadas especialmente para esta análise. Os procedimentos utilizados foram chamados de "Tradicional" e "Eco": o primeiro, com técnicas já utilizados há algum tempo em lavanderias industriais; e o segundo, mais atual, envolvendo economia de recursos e/ou mudança nos processos.

Como os procedimentos aplicadosaojeans atualmente, independentemente de serem considerados tradicionais ou ecológicos, visam tornar a aparência do jeans mais próxima da aparência que ganhava com o uso em sua origem, considerouse necessário abordar também o caminho percorrido pela calça jeans na história, que trouxe significados materiais e simbólicos a esta peça tão popular e clássica 
do vestuário. A pesquisa buscou esclarecer a diferença entre termos muitas vezes utilizados como sinônimos, como jeans, denim e índigo. A base teórica principal sobre jeans é da autora Lu Catoira $(2006,2009)$.

\section{HISTÓRIA DO JEANS}

O jeans passou por diversas mudanças ao longo de sua história, sua trajetória é ampla, tanto no sentido material como simbólico. Para Catoira (2006, p. 83), “O jeans, na verdade, já começou sua trajetória como um elemento globalizado: é um tecido francês, as primeiras roupas foram italianas, mas o mérito é do alemão Levi Strauss, e o produto virou 'febre' no mundo todo". Não somente com o intuito de proteção, quando se relaciona ao trabalho pesado, o jeans começa a ser usado como um símbolo social, quando jovens começaram a usá-lo como forma de expressão de contracultura e o item passou a destacar-se como um elemento que transcende a moda.

Segundo Catoira (2006), Levi Strauss chegou aos Estados Unidos em 1845 e tinha na sua bagagem um tecido muito resistente, então decidiu oferecer alguns pedaços para que assim os garimpeiros pudessem construir tendas de coberturas ou as coberturas dos vagões de minérios. Mas o que os garimpeiros precisavam, na verdade, era de roupas com bastante resistência às atividades pesadas, lama e terra, que os mineradores enfrentavam no dia a dia. Strauss decidiu, então, confeccionar algumas calças com este tecido reforçado, usando como molde a calça de um marinheiro genovês, e criou um modelo próprio. Como já mencionado, nascia em 1850 o primeiro jeans.

Strauss, no início, produzia as calças para os garimpeiros, mas, logo em seguida, os cowboys começaram a usá-las, pois o tecido era mais resistente e os protegia na lida com o gado. O jeans estava longe de ser um produto com 
bom caimento e bom acabamento, pois era um tecido produzido com o fio $100 \%$ algodão, com um método de tecimento plano que consiste em 2 fios, com trama de algodão cru e urdume, tingido com corante índigo. Catoira (2006) afirma que a origem do nome denim vem da junção de+nim, porque em 1853 o tecido francês era conhecido como "toile de Nimes" e fabricado na cidade de Nimes. A expressão americana acabou deixando o denim conhecido no mundo todo. Porém, desde a idade média o tecido já era utilizado para a fabricação de velas de barcos e até mesmo para as roupas dos marinheiros de Gênova, cidade que em francês significa Gênes, o que dá origem à palavra jeans.

Segundo Fabianis, Ferreti e Rocca (2014), Jacob Davis, alfaiate que produzia calças para Levi Strauss, ao confeccioná-las teve a ideia de acrescentar pequenos metais nos bolsos para evitar que rasgassem, criando assim os rebites. Mas Jacob não tinha o valor em dinheiro necessário para patentear este processo, e então sugeriu uma sociedade a Levi Strauss. Strauss e Jacob Davis, em 1873, receberam a patente 139.121, que nada mais era que a concessão para aplicar rebites de cobre nas calças de algodão cru, reforçando assim partes da calça utilizada pelos trabalhadores, especialmente bolsos.

Catoira (2009) diz que um dos primeiros concorrentes de Levi Strauss foi Henry David Lee, que na época era um fabricante de enlatados que teve a ideia de criar um macacão em denim para seus funcionários, conhecido como Lee Bib Overall. Em 1926, Lee iniciou sua fábrica de roupas, e foi o primeiro a utilizar o zíper de metal nas peças em denim.

Fabianis, Ferreti e Rocca (2014) afirmam que as calças jeans foram compradas pela Marinha dos Estados Unidos para os marinheiros usarem na Segunda Guerra Mundial, aumentando assim a clientela. Décadas depois, outra marca surge e começa a fabricar o jeans, a Wrangler. Com o sucesso deste item de vestuário, estas marcas surgidas posteriormente a Levi Strauss não prejudicaram 
seu negócio pela concorrência, pois o crescimento e a busca pelo jeans estavam cada vez maiores.

Segundo Fabianis, Ferreti e Rocca (2014), Levi Strauss já não fabricava mais as peças em denim somente para os garimpeiros, e então começou a fabricação em escala mundial, vendendo as peças a US\$1,25, e logo tornou-se milionário. O jeans, que nasceu masculino e rústico, tornou-se em 1934 uma peça feminina, com modelagem especial, podendo, deste modo, ser usado por ambos os sexos, vestindo a juventude e ajudando nas revoluções, seja sexual, social ou dentro da própria indústria têxtil.

\subsection{Da Contracultura à Moda}

A moda, como um sistema estratificador e que normatiza o vestir, tende a determinar idades, classes sociais, conferindo ares de poder, riqueza e trabalho aos itens do vestuário e a quem os possui. Lipovetsky (2009) entende a moda como um sistema inseparável do "individualismo", ou seja, alguns se adaptam, se modulam, e outros seguem rigorosamente os cânones do momento. Vivemos em uma sociedade na qual sente-se a necessidade de pertencimento a diferentes grupos, e o jeans está presente em quase todos eles como parte do visual adotado.

Sabe-se que as roupas não servem aos indivíduos apenas como forma de cobrir o corpo. Além desta necessidade, as roupas têm o intuito de comunicar, são formas de expressão, e no caso do jeans não seria diferente. "Através da história da humanidade, o vestuário é visto como uma forma de comunicação, e a moda escreveu uma linguagem visual que tem se comunicado por meio de vestimentas" (CATOIRA, 2006, p. 55).

De uniforme para trabalho à roupa de lazer, o jeans levou um certo tempo para agradar a todos. Pezzolo (2003) afirma que a introdução da calça jeans ao 
vestuário se dá a partir dos anos 50, quando passou-se a vê-lo em grandes astros do cinema, como Marlon Brando, no filme O selvagem, de 1953; James Dean, em Juventude transviada, de 1955; e da música, como Elvis Presley. As calças usadas com a bainha virada facilitavam os passos de dança frenéticos da época, o que acabou conquistando os jovens. O jeans acaba tornando-se uma peça verdadeiramente unissex. Como roupa de trabalho o jeans conquistou adeptos facilmente, porém, como roupa de lazer nem sempre alcançou o seu lugar no mundo de forma simples ou fácil.

Ressalta-se que, meio social, segundo Catoira (2006), quem usava o jeans nos anos 60 acabava sendo barrado em restaurantes, colégios, salões de festas e até mesmo em igrejas. Isso se dava pelo fato de o jeans ser usado também em protestos, sendo considerado uma forma de rebeldia dos jovens.

É importante acrescentar que a alta-costura ainda era a fonte de referência de moda, e, como era conservadora, não agradava a todos os jovens.

O imaginário juvenil daqueles anos determinou a indiferença em relação ao vestuário de haute couture, identificado como símbolo do que era velho. Com sua grande tradição de requinte, como seus modelos reservados a mulheres adultas e bem de vida, essa instituição foi desacreditada pela nova exigência do individualismo moderno: parecer jovem. (CALANCA, 2008, p. 206).

Catoira (2009) diz que na metade dos anos 60 a música foi o centro das atenções, deixando para trás os livros - foi quando surgiram bandas como Rolling Stones e Beatles. A autora se refere ao período como uma revolução psicodélica. Após essa época, a invasão do jeans na Europa foi extremamente rápida, assim como em todo o mundo. Nos anos 60, os hippies surgem com o seu jeans desbotado e customizado, pregando a paz e o amor em um movimento politizado e expressivo. Os hippies compravam os uniformes que eram utilizados pelos militares em brechós e acabavam customizando-os com flores, estampas psicodélicas - este 
comportamento influenciou grande parte do mundo. O jeans amplia seu público e a calça desbotada finalmente aparece na passarela em um desfile de moda da Calvin Klein na década de 70, causando indignação nas pessoas mais conservadoras. Para a moda, este foi um momento marcante de sua história.

Já nos anos 80, segundo Catoira (2009), a calça jeans surge em um estilo mais break', que com Michael Jackson tornou-se um estilo de dançar. É tempo de jeans com brilho e sem lavagens, somente o denim na cor índigo. Desde então, o jeans não foi mais o mesmo, novas técnicas começaram a ser usadas para que o jeans pudesse chegar em vários tons, e tipos de lavagem. Década após década, o jeans foi mudando, mas podemos perceber que esses métodos de lavanderia quase sempre remetem ao jeans em seu surgimento original, com desgastes e desbotamento causados por seu uso em trabalhos pesados. O comparativo que o estudo apresenta adiante demonstra como outros processos mais avançados vêm sendo incorporados às lavações e permitem atualizações desta peça clássica.

\section{JEANS, DENIM E ÍNDIGO}

Durante a leitura exploratória para esta pesquisa, notou-se que há termos muitas vezes utilizados como sinônimos, mas que na verdade representam coisas diferentes relacionadas à calça jeans. Para entender melhor sobre o assunto, é preciso deixar clara a definição entre jeans, denim e índigo.

O jeans se refere ao conceito da roupa criada por Levi Strauss, feita com tecido de algodão e tingida com o corante índigo. A calça ficou conhecida como fivepockets por ser tratar de uma peça com cinco bolsos. Segundo Oliveira (2008, p. 23), "Jeans não é somente um tecido, mas sim um conceito de roupa, um estilo, que tem

[1] Breakdance (também conhecido como breaking ou b - boying em alguns lugares) é um estilo de dança de rua. Parte da cultura do Hip-Hop criada por afro-americanos e latinos na década de 1970, em Nova Iorque, nos Estados Unidos, normalmente é dançada ao som do Hip-Hop ou de Breakbeat (LOPES, 2005). 
uma enorme variação de tipos de tecido e formas". O nome do tecido utilizado na confecção do jeans é o denim blue índigo.

Originalmente, esse tecido pesava $14 \mathrm{oz}^{2}$, ou até mais, por se tratar de um tecido bem pesado e resistente. Com o passar do tempo, as peças foram produzidas em outras gramaturas, para atender a um número maior de consumidores.

Índigo é o corante utilizado para o tingimento do denim. Conforme Catoira (2006, p. 83), este corante é extraído das plantas orientais Indigofera e Isati tinctoris, e encontra-se registrado na alfândega de Gênova desde 1140. O corante sintético foi colocado no mercado pela Basf, em 1897. A versão sintética tem um valor muito mais baixo que o natural, pois o corante natural dependia da maceração e fermentação das plantas.

Segundo Silva (2014), na década de 60, logo após o surgimento do denim, novos filamentos foram inseridos, dando assim maior maleabilidade e conforto às peças. Esses filamentos são conhecidos como poliéster e elastano, que, ao serem inseridos junto ao algodão, permitiam novas formas e aplicações para o tecido, conferindo à peça produzida um melhor acabamento e maior valor agregado.

Ao longo da história, o denim se caracterizou como um tecido de grande durabilidade e popularidade, por ser um tecido de fácil lavagem, resistente e utilitário, o que permitiu que fosse considerado um nivelador social. Como peça de vestuário, conseguiu sobreviver a diversas mudanças sociais ou estéticas, e vem atravessando gerações. Segundo Catoira (2006), é o material mais manejado pela indústria têxtil nos últimos 150 anos.

[2] Onças ou oz é a medida de peso inglesa, que equivale a 28,34 gramas, e quando se diz que um tecido tem $12 \mathrm{oz}$, pretende-se dizer que um metro quadrado de tecido pesa $12 \mathrm{oz}$, ou seja, $28,34 \times 12$, que é igual a 340,08 gramas por metro quadrado de tecido (OLIVEIRA, 2008). 


\section{SUSTENTABILIDADE NA MODA: O CASO DO JEANS}

O ciclo de vida de um produto é a história completa de um produto passando por todas as suas fases. Para Gwilt (2014), o ciclo de vida de um produto de moda pode ser dividido em cinco etapas principais: design, produção, distribuição, uso e fim da vida. Aplicar a abordagem do ciclo de vida ao design de moda requer avaliar todas as etapas de uma peça e considerar os efeitos socioambientais causados por elas. É pensando a partir do ciclo de vida de uma peça que o designer pode exercer alguma influência ou melhoria sobre as peças.

Figura 1 - Impacto durante o ciclo de vida, pesquisa Levis

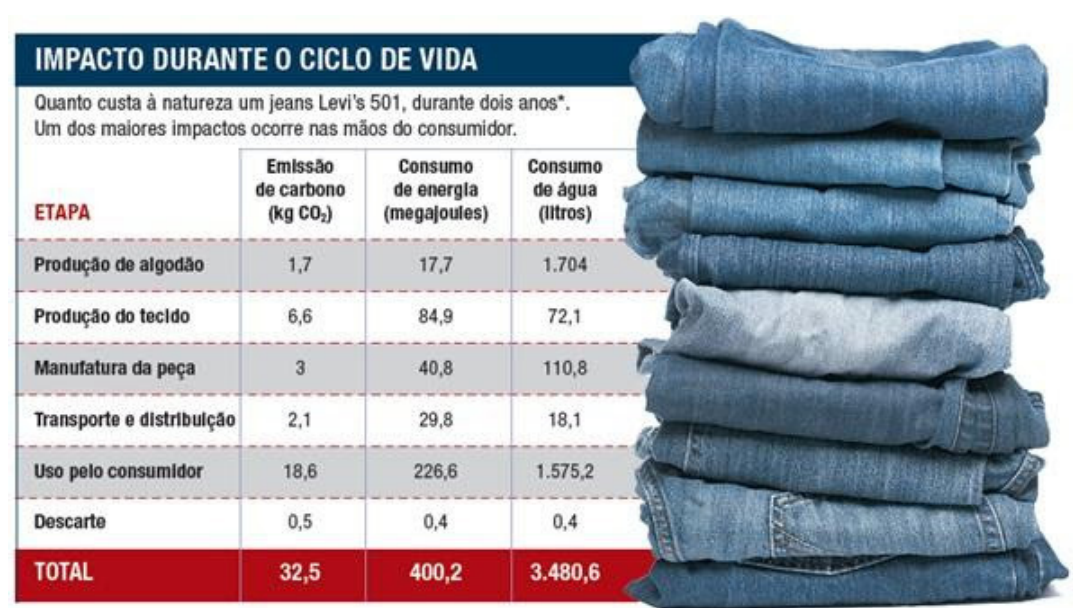

-Um exemplar da Levi's com lavagem a pedra em tom médio, lavada uma vez por semana durante dols anos.

Fonte: Bender (2011)

Na figura 1, é possível analisar os resultados de uma pesquisa feita em 2009 pela marca Levi's, a partir da observação dos impactos do ciclo de vida do tradicional jeans 501 da marca. Os dados apresentados mostram que o uso pelo consumidor é o que gera o maior consumo de água. Mesmo que este artigo tenha a delimitação de mostrar o comparativo entre dois métodos de lavanderia, a 
pesquisa da Levis acrescenta o entendimento do impacto no uso, e esta é, então, mais uma etapa do ciclo que precisa ser melhorada. Inclusive, é analisando todo o ciclo de vida do produto de moda que o designer pode agir para projetar melhorias. Algumas delas podem surgir em processos industriais de lavanderia.

A sustentabilidade na moda está presente desde a década de 60. Os hippies, já citados na contextualização histórica deste estudo, compravam seus jeans em brechós, e desde então outras novas ações para a redução do impacto ambiental vêm sendo tomadas. Gwilt (2014) diz que, mesmo o foco ainda sendo a procura por materiais adequados, a indústria moderna da moda já percorre outros caminhos diferentes, que vão além das preocupações com os materiais corretos. Conforme Oliveira (2015, p. 49), “o princípio da sustentabilidade aponta uma resposta para a integração do ambiente, da equidade social a uma nova racionalidade produtiva, com vistas a uma ordem econômico-ecológica globalizada". Sendo assim, a moda não pode fundamentar sua busca por produtos mais sustentáveis apenas na matéria-prima, é preciso que haja modificações em todas as etapas da cadeia produtiva, considerando o ciclo de vida total.

Como a sustentabilidade tem sido um dos assuntos mais comentados nos últimos tempos, as lavanderias industriais também vêm adotando um sistema mais sustentável para a lavagem das peças em denim. Nelas, já foram lançados diversos produtos de linha eco, que contam com a preocupação ambiental na sua fabricação e aplicação. É possível citar exemplos como as enzimas ${ }^{3}$ ecológicas que são aplicadas por pulverização, podendo economizar vários litros de água por peça. Anteriormente, eram utilizadas enzimas por esgotamento, que precisavam de muito mais água para a aplicação, pois as peças precisavam passar por enxágue

[3] Enzimas são moléculas orgânicas de natureza proteica, e agem nas reações químicas das células como catalisadoras, ou seja, aceleram a velocidade dos processos sem alterá-los. Geralmente, são os catalisadores mais eficazes, por sua alta especificidade. Sua estrutura quaternária é quem determinará sua função, a que substrato ela se acoplará para acelerar determinada reação (COSTA, 2012, 2015). 
para a retirada das enzimas. Com as enzimas sendo pulverizadas, consegue-se obter um resultado mais bonito e de maior contraste nas peças. As enzimas podem ser utilizadas no processo de desengomagem e estonagem, e contribuem para o clareamento das peças.

Outro produto já disponível é o chamado used ecológico, que substitui a aplicação do permanganato de potássio. Os bigodes e detonados já podem ser feitos a laser, economizando mais tempo e deixando todas as peças iguais em uma produção. O laser funciona como substituto para os efeitos que usam permanganato de potássio e para os lixados, e evita que o funcionário faça movimentos repetitivos, minimizando o risco de LER ${ }^{4}$. A utilização de produtos ecológicos para as lavanderias industriais possibilita a inutilização do hipoclorito de sódio e do permanganato de potássio. O uso de produtos socioambientalmente corretos pode trazer inúmeros benefícios para o meio ambiente, e também pode diminuir o consumo de energia e água pelas empresas. Como será visto adiante, também é possível que as peças fiquem mais bonitas, com cores e contrastes mais vivos, mantendo a qualidade do denim, pois os procedimentos não danificam a fibra do tecido.

O uso de permanganato de potássio pode ser prejudicial à saúde. Em contato com outros produtos, o elemento corre risco de reação explosiva, pois favorece a combustão de materiais combustíveis, e, ao entrar em contato com a pele ou roupas, pode provocar manchas, sendo necessário cuidado ao manuseá-lo. Oliveira (2008) diz que sua armazenagem deve ser feita separada de outros ácidos, pois pode ser um contaminante para as outras substâncias. Deve-se evitar lugares com mudanças de temperatura e exposições ao ar. O uso de hipoclorito de sódio pode provocar irritações às vias aéreas, danos aos olhos, dores de cabeça, além de queimaduras na pele e intoxicação. Segundo Oliveira (2008), o hipoclorito de sódio no processo de oxidação libera o ácido hipocloroso, e pode ser prejudicial ao

[4] Lesões associadas ao esforço de repetição (BRUNA, 2019). 
meio ambiente e à saúde humana, sendo extremamente perigoso quando entra em contato com ácidos de qualquer natureza. Seu armazenamento deve ser feito longe de fontes de calor e em recipientes escuros.

Atualmente, existe um programa de pesquisa avançado chamado Gateway $Z D H C^{5}$, que serve para verificar se os produtos que estão sendo utilizados pelas indústrias da cadeia têxtil estão de acordo com os cuidados devidos ao meio ambiente. O programa promove a busca por alternativas e produtos químicos mais seguros e a substituição por sustentáveis. A ZDHC investe nessas melhorias para proteger o consumidor, trabalhador e o meio ambiente. A responsável pela inspeção, verificação, testes e certificação do programa é a SGS ${ }^{6}$, que é líder mundial no assunto.

As mudanças e melhorias ainda estão no início para o setor de lavanderias, porém há empresas realizando pesquisas e testes, e logo a indústria terá outras novas tecnologias e soluções para desenvolvimentos mais sustentáveis. A vicunha têxtil, que é uma das maiores indústrias têxteis do mundo e líder em diversos segmentos, junto ao movimento $\mathrm{Ecoera}^{7}$, calculou pela primeira vez o consumo de água de uma calça jeans no Brasil desde o plantio até o consumidor final. Este cálculo foi feito a partir de um programa chamado Pegada hídrica vicunha, e foi dividido em três indicadores de pegada hídrica: a verde, a azul e a cinza, e com isso

[5] Abordagem holística para a questão dos produtos químicos perigosos utilizados nos processos têxteis (ZDHC, 2019).

[6] Empresa de inspeção que ajuda a reduzir riscos, a controlar a qualidade e quantidade e a cumprir todos os requisitos regulamentares em diferentes regióes e mercados (SGS, 2019).

[7] O Portal Ecoera é o resultado de um trabalho conjunto, uma força-tarefa que envolveu empresários, profissionais liberais, artesãos, designers, jornalistas e participantes da sociedade civil, todos movidos pelo mesmo propósito: fazer diferença na sociedade e no meio ambiente. (BEM-VINDOS ..., 2017). 
eles obtiveram o resultado de 5,196 litros de água por calça. Este número é uma média do Brasil, e foi desconsiderada a parte do consumidor final, pois o efluente da máquina de lavar roupas não é exclusivo do jeans. Este estudo é inédito no Brasil e muito importante para que todos tenham conhecimento e se preocupem cada vez mais com os efeitos da produção e uso de peças jeans para o meio ambiente.

\section{METODOLOGIA}

Esta pesquisa, de caráter multidisciplinar, envolve áreas diferentes do conhecimento em busca de um objetivo final. Foi realizado um estudo de caso para considerar o resultado de dois processos diferentes de lavanderia aplicados a um mesmo de produto de moda. Segundo Yin (2005), o estudo de caso pode ser tratado como uma importante estratégia metodológica para a pesquisa em ciências humanas, pois permite ao investigador um aprofundamento em relação ao fenômeno estudado, revelando nuances difíceis de serem enxergadas a olho nu. A pesquisa é de natureza aplicada e experimental. $O$ estudo é qualitativo, pois se dá por meio de investigação a partir de observações extraídas de pessoas, lugares ou métodos. Segundo Godoy (1995), os estudos denominados qualitativos têm como preocupação fundamental o estudo e a análise do mundo empírico em seu ambiente natural.

Durante o estudo, foram coletados dados, e cada procedimento de beneficiamento do jeans foi analisado, levando em consideração os produtos utilizados e o tempo e a quantidade de água gastos em cada tipo de lavação. Visualmente, também foram avaliadas características esperadas em um jeans de qualidade, como contraste entre cores, marcação de costuras e valorização dos aspectos exclusivos de cada tecido.

O estudo contextualizou a história do jeans desde o seu surgimento, em 1850, as etapas de lavanderia e a sustentabilidade na moda relacionada ao 
Lavanderia em jeans e a sustentabilidade... ecológicos

LUIZ, S.; VALENTIM, A. F.

A sustentabilidade na moda está presente desde a década de 60. Os hippies, já citados na contextualização histórica deste estudo, compravam seus jeans em brechós, e desde então outras novas ações para a redução do impacto ambiental vêm sendo tomadas. 
jeans com uma pesquisa bibliográfica feita através de livros e artigos periódicos publicados. Informações próprias dos produtos citados na pesquisa e utilizados no desenvolvimento das peças foram extraídos dos manuais de cada fornecedor. A seguir, são apresentadas as etapas e os dados coletados no estudo de caso, que detalhou o processo de desenvolvimento das duas peças comparadas.

\section{PROCESSOS DE BENEFICIAMENTO EM LAVANDERIA - UM ESTUDO DE CASO}

Os processos de beneficiamento em lavanderias industriais são de extrema importância, pois são eles que fazem a melhoria no denim cru, deixando as peças confortáveis; assim, de certo modo, participam da moda ditando e seguindo as tendências. Nesta seção, além dos autores utilizados para embasar o estudo, a experiência profissional no ramo de lavanderia industrial da autora e da orientadora também são utilizadas na descrição dos métodos e suas aplicações, uma vez que há poucas fontes bibliográficas sobre o assunto em português.

O tecido cru não é tão confortável quanto o tecido já lavado, portanto ele passou a ser lavado antes de ser colocado à venda. No caso do algodão, por exemplo, a etapa de preparação inicia pela desengomagem e alvejamento, podendo, muitas vezes, ser realizada em conjunto, utilizando produtos químicos para adiantar esses processos. Em todos esses procedimentos, deverão ser realizados controles de tempo, temperatura e concentração de produtos químicos, para que os resultados sejam atingidos como o esperado. A etapa de desengomagem descrita acima e os controles utilizados em sua execução fazem parte de apenas um exemplo, considerando que a quantidade de lavagens que se pode aplicar a uma peça crua é imensurável. Dessa forma, não existe uma mesma sequência de métodos a serem aplicados, pois tudo depende do objetivo final. 
Segundo Oliveira (2008), as lavanderias de jeans nascem no início dos anos 80, após a produção do denim em larga escala. As lavanderias em jeans iniciaram com a aplicação dos envelhecimentos e os desbotamentos, feita a partir do uso do permanganato de potássio, que é um agente oxidante que ao entrar em contato com a peça acaba corroendo a cor do índigo, causando um efeito esbranquiçado. Após a aplicação do permanganato, a peça é mergulhada em solução responsável pela neutralização, revelando o efeito clareador do permanganato de potássio. Outro agente clareador também utilizado é o hipoclorito de sódio, e este, por sua vez, também necessita de uma neutralização ao final de seu processo.

Outra forma de clareamento e envelhecimento de peças que ficou conhecido como Stone Washed é feita com o uso de pedras pomes colocadas dentro das lavadoras, que, ao entrarem em atrito com a peça em denim, provocam o desgaste do índigo. Existe também o clareamento localizado, obtido nas peças por meio da aplicação de permanganato de potássio com uma pistola de ar comprimido, deixando assim apenas algumas partes da peça mais desbotadas - esta técnica é conhecida como Used.

Inicialmente, as lavanderias eram responsáveis apenas por deixar as peças mais maleáveis para o uso, e conseguiam isso através das técnicas de amaciamento, que mantêm a mesma tonalidade do índigo, dando a ele apenas maciez. A partir do momento que o jeans incorporou tendências de moda, alguns processos foram adicionados a ele: bigodes que podem ser feitos na lixa, no laser ou na prensa para dar efeito 3D nas peças; detonados, que são os rasgos, e podem ser feitos em vários tamanhos e em qualquer lugar da peça; lang, que pode ser feito na lixa, manualmente, ou no laser; ripped, nas barras e bolsos, dando o efeito de pequenos rasgos; corrosão, que é a aplicação do permanganato de potássio com um cotonete nas bordas de bolsos, costuras e detalhes, deixando a peça mais clara nessas partes; amarras, que são feitas com uma espécie de rede, em que a peça é colocada dentro e amarrada, garantindo assim marcações mais evidentes. Há 
ainda a aplicação de resinas; marmorizado; tingimentos. Os procedimentos para o beneficiamento do denim e suas combinações são inúmeras, e vêm aumentando cada dia mais. A figura (2) abaixo representa uma das possíveis combinações de processos químicos e físicos aplicáveis ao denim na etapa de lavanderia.

Figura 2 - Processos de beneficiamento e sua aplicação no jeans

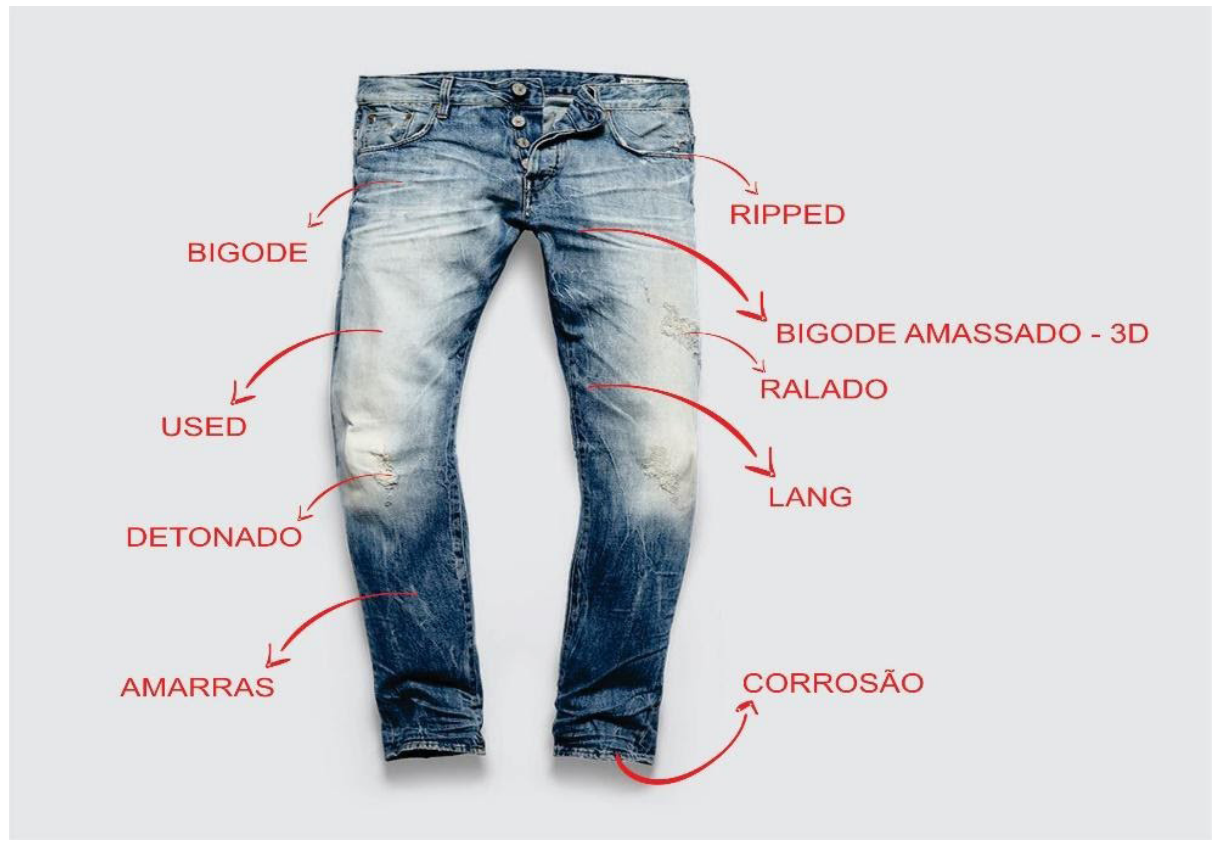

Fonte: Desenvolvido pela autora ${ }^{8}$ (2019)

[8] Adaptado de imagem disponibilizada em: https://br.pinterest.com/
pin/571746115192380907/.




\subsection{Comparativo entre os Processos de Lavanderias Aplicados ao Jeans}

O modelo escolhido para o desenvolvimento das calças foi o $\mathrm{Mom}^{9}$, por ser tradicional na Levi's e nos lembrar da época que Strauss criou as calças jeans. A lavanderia clara nos remete aos trabalhadores da época, que obtinham esses resultados somente com o uso das peças no trabalho pesado do dia a dia.

A empresa Criativa Têxtil está há 18 anos no mercado, e foi a responsável pela confecção e beneficiamento das peças. Por ser a empresa onde a autora trabalha, cada etapa foi observada e acompanhada pessoalmente por ela. A Criativa tem uma grande preocupação com o meio ambiente há muito tempo: toda a água utilizada na lavanderia é tratada, despejada em um açude próprio e reutilizada.

O tecido utilizado para a confecção das calças foi o Dusk, da Santana Textiles, que é $100 \%$ algodão, pesa $120 z$, e, segundo a ficha técnica do produto disponibilizada pela Santana, o artigo é rígido, pesado e na cor blue, ideal para trabalhar lavagens mais agressivas.

No processo tradicional, foram utilizadas pedra pomes para a estonagem da calça, junto de permanganato de potássio e hipoclorito de sódio, para se obter o desbotamento desejado; o bigode foi feito na lixa, manualmente, e para fazer o used, aplicou-se o permanganato de potássio com uma pistola de ar comprimido. É importante lembrar que este método tradicional ainda é utilizado por lavanderias no Brasil, e na empresa onde foi realizada a experiência ele era utilizado até pouco tempo atrás. As enzimas e procedimentos utilizados foram por esgotamento ${ }^{10}$.

[9] Esses jeans são caracterizados por quatro coisas, principalmente: eles têm cintura alta, são mais larguinhos, de corte reto e são (na maioria das vezes) cor de jeans meio desbotado. Mon em inglês quer dizer mãe e essas calças eram usadas por mulheres especialmente nos anos 80 e 90 (NOGUEIRA, 2018).

[10] Remoção total de um líquido (ESGOTAMENTO..., 2019). 
No processo ecológico, utilizou-se a linha de produtos químicos Eco (Garmon ${ }^{11}$ ), na qual foram aplicadas as enzimas por nebulização ${ }^{12}$; o bigode foi feito a laser, e não foram utilizados permanganato de potássio ou hipoclorito de sódio. Ainda assim, o used foi aplicado com a pistola de ar comprimido manualmente. Poucas lavanderias no Brasil fazem o uso de produtos químicos da linha ecológica, afinal ela ainda é uma novidade no mercado. Apesar desta pesquisa ser qualitativa, utiliza dados quantitativos em sua análise, como mostram os resultados apresentados na tabela (figura 3), referentes a processos aplicados nas duas lavações: tradicional e ecológica.

Figura 3 - Tabela de processos

\begin{tabular}{|c|c|c|c|}
\hline PROCESSO TRADICIONAL & TEMPO & AGUA & OBSERVACÖES \\
\hline BIGODE & 5 minutos & & LIXA MANUAL \\
\hline DESENGOMAGEM + ENXÁGUE & 10 minutos & $4,200 \mathrm{~L}$ & \\
\hline ESTONAGEM + ENXÁGUE & 30 minutos & $4,200 \mathrm{~L}$ & ENZIMAA POR ESGOTAMENTO \\
\hline ESTONAGEM & 60 minutos & $4,200 \mathrm{~L}$ & ENZIMA POR ESGOTAMENTO + 50\% PEDRA POMES \\
\hline INATIVAÇÄO DA ENZIMA + ENXÁGUE & 5 minutos & $2,400 \mathrm{~L}$ & PARA NÄO APODRECER 0 TECIDO \\
\hline CLAREAMENTO COM CLORO & 50 minutos & $4,200 \mathrm{~L}$ & USO DE HIPOCLORITO DE SÓDIO \\
\hline NEUTRALIZAÇÄO + ENXÁGUE & 15 minutos & $4,200 \mathrm{~L}$ & CORTAR AÇÃO DO HIPOCLORITO DE SÓDIO \\
\hline SECAGEM & 30 minutos & & \\
\hline USED COM PERMANGANATO DE SÓDIO & 5 minutos & 100ML & APLICAÇÄO MANUAL COM PISTOLA DE AR COMPRIMIDO \\
\hline NEUTRALIZAÇÄO + ENXÁGUE & 15 minutos & $4,200 \mathrm{~L}$ & REVELAR O EFEITO ESBRANOUICCADO DA PECCA \\
\hline ALVEJAMENTO + ENXÁGUE & 15 minutos & $4,200 \mathrm{~L}$ & PRODUTO ANTIMIGRANTE \\
\hline AMACIAMENTO & 15 minutos & $4,200 \mathrm{~L}$ & PADRÄO - USO DE AMACIANTE \\
\hline SECAGEM & 30 minutos & 600ML & \\
\hline PROCESSO ECOLÓGICO & TEMPO & ÁGUA & OBSERVACŌES \\
\hline BIGODE & 3 minutos & & LASER \\
\hline ESTONAGEM NEBULIZADA & 50 minutos & $2,400 \mathrm{~L}$ & GARMON \\
\hline INATIVAÇÄO DA ENZIMA + ENXÁGUE & 5 minutos & $2,400 \mathrm{~L}$ & PARA NÄO APODRECER O TECIDO \\
\hline CLAREAMENTO NEBULIZADO & 30 minutos & 300ML & PARA OXIDAÇÄO E ATIVAÇĀO DO PRODUTO \\
\hline SECAGEM & 40 minutos & & \\
\hline USED ECOLÓGICO & 5 minutos & 100ML & PARA SUBSTITUIR O PERMANGANATO \\
\hline ALVEJAMENTO ECOLÓGICO + ENXÁGUE & 15 minutos & $4,200 \mathrm{~L}$ & SEM HIPOCLORITO DE SÓDIO \\
\hline NEUTRALIZAÇÄO + ENXÁGUE & 15 minutos & $4,200 \mathrm{~L}$ & REVELAR O EFEITO ESBRANOUICCADO DA PECCA \\
\hline AMACIAMENTO ECOLÓGICO & 10 minutos & 600H:AL & AMACIANTE DA LINHA ÉCO \\
\hline SECAGEM & 30 minutos & & \\
\hline
\end{tabular}

Fonte: Desenvolvido pela autora (2019)

[11] Garmon Chemicals é uma empresa líder em pesquisa, desenvolvimento, marketing de soluções químicas para a indústria do vestuário, e referência em qualidade de produtos e práticas responsáveis (GARMON KEMIN GROUP, 1985).

[12] Ato ou efeito de nebulizar, de pulverizar um líquido utilizando um nebulizador; pulverização (NEBULIZAÇÃO ..., 2019). 
A moda não pode fundamentar sua busca por produtos mais sustentáveis apenas na matériaprima, é preciso que haja modificações em todas as etapas da cadeia produtiva, considerando o ciclo de vida total. 
Figura 4 - Foto das peças desenvolvidas para comparativo.

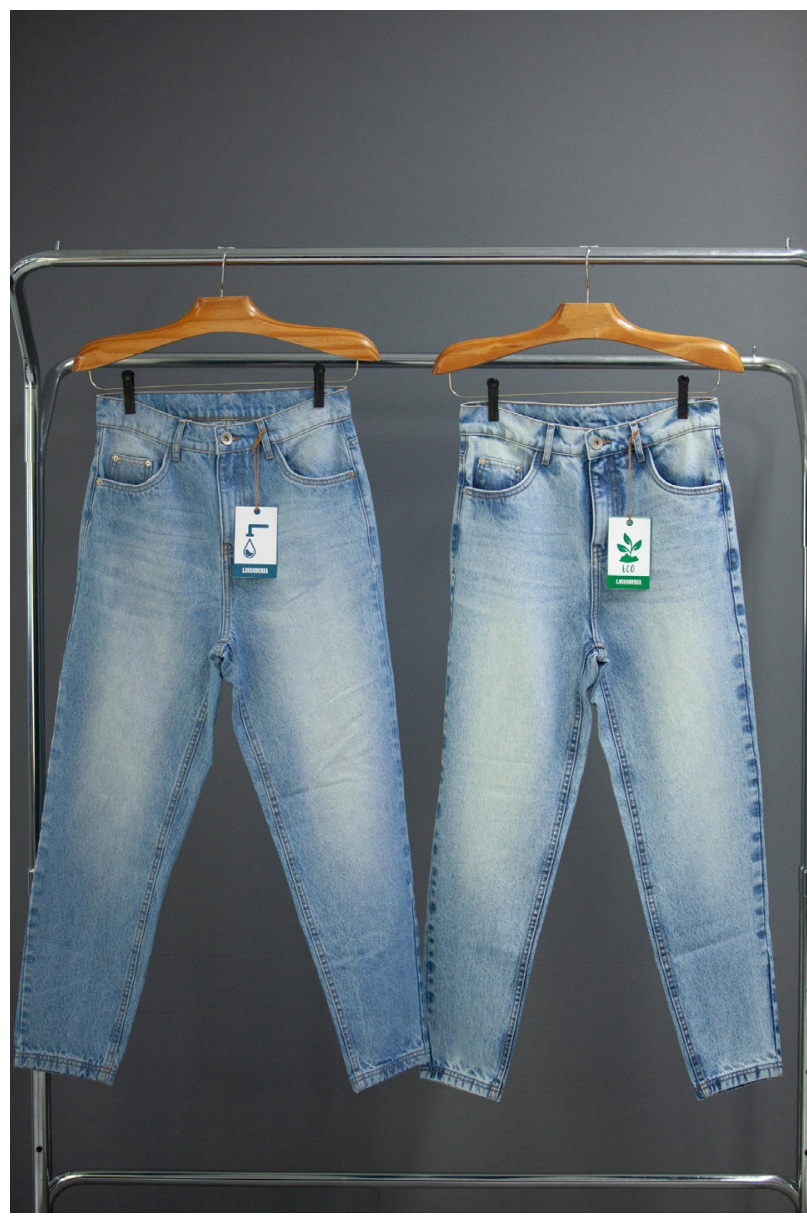

Fonte: Desenvolvido pela autora (2019)

Com a foto (figura 4) das duas calças desenvolvidas para análise, também é possível descrever algumas características visuais que as diferenciam. Na peça com lavagem tradicional, à esquerda, percebe-se um aspecto mais fosco, sem tantos pontos de luz, com menos marcações nas costuras e menor contraste entre partes claras e escuras. No comparativo do toque, a peça tradicional também é mais áspera. Isso acontece porque o método tradicional com pedras acaba agredindo mais o tecido. 
Na peça com lavagem Eco, à direita, as enzimas desbotam somente o corante índigo da peça, e a fibra permanece inalterada.

O custo também é um dos diferenciais: a peça tradicional custou $\mathrm{R} \$$ 52,56 , e a peça $E c o, R \$ 57,38$. Neste valor, estão inclusos o tecido, a confecção, o beneficiamento e o acabamento. No beneficiamento, quando são desenvolvidos os procedimentos de lavanderia, o custo foi $R \$ 6,80$ para o processo tradicional e $R \$$ 11,02 para o processo eco. Cabe lembrar que este custo se refere exclusivamente aos dois produtos feitos para esta análise, assim ele pode mudar dependendo da escolha da lavação, pois se forem escolhidas muitas combinações de métodos esse valor será mais alto.

\section{CONSIDERAÇÕES FINAIS}

O jeans sempre despertou muito interesse tanto para a orientadora desta pesquisa quanto para a autora, que no projeto final do curso desenvolveu uma coleção toda em denim. Além da experiência com a coleção e o contato diário com lavanderia e procedimentos de beneficiamento de peças em denim, ao escrever este trabalho teórico o auxílio de livros e artigos engrandeceu ainda mais o conhecimento sobre o assunto. As leituras foram fundamentais e proporcionaram um grande avanço no entendimento do contexto que envolve a história do jeans. Todo o trajeto da pesquisa auxiliou profissionalmente a autora, além das etapas teóricas, cada processo prático foi acompanhado por ela na lavanderia onde trabalha, exigindo assim muito mais dedicação e aplicação de conhecimento.

O jeans faz parte da vida das pessoas há muito tempo, e, ao estudá-lo, pode-se dizer que é uma peça que sofreu muitas modificações ao longo da história, mas ainda assim é muito importante para o vestuário, servindo como roupa de trabalho, lazer e como símbolo de liberdade, sem distinção de classe e idade. Sua 
existência como item explorado pela moda mostra que, ao mesmo tempo que se adapta a desejos e tempos diferentes, sobrevive como clássico, e isso demonstra também sua rebeldia.

É provável que nenhum outro tecido conseguiu sobreviver a tantas mutações da moda como o denim, produzido em larga escala nos anos 80, levando ao surgimento das lavanderias de beneficiamentos em jeans. Este foi um passo importante para a história do denim, pois ele deixou de ser uma peça grosseira e começou a receber modos de desbotamento e envelhecimento. Este momento também mostra como a moda o incorporou ao seu universo e passou a propor renovações constantes.

Nos dias atuais, as lavanderias industriais estão crescendo e acompanhando cada vez mais as necessidades mercadológicas. Pode-se pensar, a partir dessas reflexões, que inovações no setor continuarão acontecendo, principalmente quando se fala em sustentabilidade. O futuro da moda é dependente destes avanços.

Desde a década de 1960, os conceitos de sustentabilidade eresponsabilidade social fazem parte da indústria da moda, mas nunca estiveram tão fortes como atualmente - algumas empresas buscam, então, adequar-se aos novos tempos. Ao realizar o comparativo entre as lavações, pode-se perceber que a lavanderia constitui uma das etapas na cadeia produtiva que causa mais impacto ao meio ambiente, tanto pelo uso de produtos químicos quanto pelo alto consumo de água e energia. Com o procedimento eco, é possível reduzir esses pontos de impacto em mais de um aspecto: na parte do beneficiamento, reduz-se a quantidade de água, o tempo dos métodos, e esteticamente as peças ficam mais bonitas. Quando se pensa no ciclo de vida completo do produto, são reduzidos os danos que processos mais nocivos trariam às fibras pelo fato de não agredirem muito o tecido; assim os resultados permanecem por muito mais tempo, e a peça se torna mais durável. Este fator é de extrema importância, porque quando o cliente compra uma peça 
em jeans nem sempre pode avaliar a durabilidade dela. Esteticamente, a peça pode satisfazer os anseios do consumidor, porém nem todos possuem conhecimento para avaliar o quanto os métodos aplicados atingiram negativamente as fibras. $O$ processo eco, de maneira geral, garante mais qualidade ao produto.

Observando e identificando quais etapas são possíveis de aprimoramento e mudanças, algumas melhorias vêm sendo introduzidas nas lavanderias industriais, como o laser, a máquina de ozônio, os produtos químicos e corantes menos danosos ao meio ambiente. Com o laser, utilizado para clarear pontos específicos da peça, diminui-se ou elimina-se o uso de produtos como permanganato de potássio e hipoclorito de sódio. Com isso, aumentam também a qualidade e a produtividade; o mesmo efeito é reproduzido em todas as peças de maneira igual e de forma mais rápida, pois o processo passa a ser computadorizado, uma vez que o colaborador apenas posiciona a peça e o laser faz o trabalho. A máquina de ozônio reduz o consumo de água, porque a peça não precisa estar imersa. Com relação aos produtos químicos e corantes, por mais que a indústria esteja procurando e lançando produtos que tornem os procedimentos menos poluidores, eles ainda se encontram em fase inicial; alguns, em fase de teste, e por isso é difícil precisar a dimensão de suas melhorias. Para este comparativo, o uso de produtos eco manteve a qualidade do tecido, reduziu o uso de água e o tempo de produção.

Além de perceber avanços no lançamento de equipamentos e produtos, assim como nas formas de aplicação dos métodos, considera-se importante acrescentar que toda a cadeia têxtil precisa estar voltada ao aprimoramento de suas práticas, pois uma etapa é dependente da outra.

Outros parâmetros poderiam ser avaliados neste estudo, todos eles envolvendo conhecimentos mais técnicos do setor de lavanderia industrial e da parte química. No entanto, para o objetivo desta pesquisa, que está mais voltado à 
área do design de moda, o comparativo foi capaz de trazer elementos suficientes para uma análise aprofundada, ao serem observados tanto aspectos visuais quanto materiais.

Para o designer de moda, os conhecimentos advindos desta pesquisa colaboram para a introdução de formas mais sustentáveis de produção em jeans, uma vez que o resultado não só não deixa a desejar em relação aos processos já estabelecidos como torna o produto melhor e mais bonito. A procura por formas mais sustentáveis de produzir efeitos e beneficiar o denim pelos designers também aumenta a disponibilidade destes produtos aos consumidores, incentivando um consumo mais consciente.

Para além do designer, o consumidor tem um papel importante na redução de impactos ao meio ambiente. Com esta pesquisa, é possível compreender a dimensão que o uso pelo consumidor traz em termos de utilização de recursos como a água. Não cabe ao consumidor apenas exigir melhorias por parte da indústria, é papel dele também buscar conhecimento sobre marcas corretas socioambientalmente, com o entendimento de que sua atuação durante o uso traz consequências ao meio ambiente.

Compreende-se que ainda é preciso avançar em termos de pesquisas como a Gateway ZDHC e a Pegada hídrica vicunha, pois elas apresentam dados e acrescentam informações que auxiliam em pesquisas acadêmicas como esta, contribuindo para o avanço tecnológico no setor têxtil e de moda.

Finalmente, ao perceber mudanças nos rumos da moda, com relação à sua própria sobrevivência, percebe-se que a manutenção da moda enquanto promotora de novidades está vinculada à preservação e diminuição cada vez mais eficazes do uso de recursos naturais. 
Desde a década de 1960, os conceitos de sustentabilidade e responsabilidade social fazem parte da indústria da moda, mas nunca estiveram tão fortes como atualmente - algumas empresas buscam, então, adequar-se aos novos tempos. 
Projética, Londrina, v. 12, n. 1, p. 297-326, março 2021

\section{REFERÊNCIAS}

1. BEM-VINDOS ao Portal Ecoera! PortaL Ecoera, São Paulo, 27 nov. 2017. Redação. Beleza. Disponível em: https://www.portalecoera.com.br/moda/ bem-vindos-ao-portal-ecoera/. Acesso em: 25 jun. 2019.

2. BENDER, Valesca. Calça Jeans: vilão do meio ambiente. 2011. Disponível em: https://ativarsentidos.com.br/tato/calca-jeans-vilao-do-meio-ambiente/. Acesso em: 25 jun. 2019.

3. BRUNA, Maria Helena Varella. Lesão por esforço repetitivo (LER/DORT). Portal Dráuzio Varella, Rio de janeiro, 2019. Disponível em: https://drauziovarella. uol.com.br/doencas-e-sintomas/lesao-por-esforco-repetitivo-ler-dort/. Acesso em: 25 jun. 2019.

4. CALANCA, Daniela. História social da moda. São Paulo: Senac São Paulo, 2008.

5. CATOIRA, Lu. Jeans, a roupa que transcende a moda. Aparecida SP: Ideias \& Letras, 2006. 132 p.

6. CATOIRA, Lu. Moda Jeans: fantasia estética sem preconceito. São Paulo: Ideias \& Letras, 2009.

7. COSTA, Yanna Dias. Enzimas. Campinas: Unicamp, 2012. Graduação em Ciências Biológicas. Disponível em: https://www.infoescola.com/bioquimica/ enzimas/. Acesso em: 25 jun. 2019. 
8. COSTA, Yanna Dias. Enzimas. São Carlos: UFSCar; São Paulo: Fundação Parque Zoológico, 2015. Mestrado Profissional em Conservação da Fauna Silvestre. Disponível em: https://www.infoescola.com/bioquimica/enzimas/. Acesso em: 25 jun. 2019.

9. ESGOTAMENTO. In: PRIBERAM dicionário. Online. Disponível em: https:// dicionario.priberam.org/esgotamento. Acesso em: 25 jun. 2019.

10. FABIANIS, Valeria Manferto de; FERRETI, Alberta; ROCCA, Federico. Questão de estilo: 20 itens icônicos que mudaram a história da moda. Tradução de Paula Borges. São Paulo: Manole, 2014.

11. GARMON Kemin Group. Our history: more than 30 years in the garment finishing industry. San Marino: Garmon Chemicals, 1985. Disponível em: http://www.garmonchemicals.it/company\#history. Acesso em: 25 jun. 2019.

12. GODOY, Arilda Schmidt. Introdução à pesquisa qualitativa e suas possibilidades. RAE-Revista de Administração de Empresas, São Paulo, SP, v. 35, n. 2, p. 57-63, 1995.

13. GWILT, Alison. Moda sustentável: um guia prático. São Paulo: Gustavo Gilli, 2014.

14. LIPOVETSKY, Gilles. O império do efêmero: a moda e seu destino nas sociedades modernas. Tradução de Maria Lucia Machado. São Paulo: Companhia das Letras, 2009.

15. LOPES, Nuno. Breakdance. Estilos. Just Dance School-JDS, Leça da Palmeira, PT, 2005. Disponível em: http://www.justdanceschool.pt/estilos/. Acesso em: 25 jun. 2019. 
Projética, Londrina, v. 12, n. 1, p. 297-326, março 2021

16. NEBULIZAÇÃO. In: PRIBERAM dicionário. Online. Disponível em: https:// dicionario.priberam.org/nebulização. Acesso em: 25 jun. 2019.

17. NOGUEIRA, Vanessa. A calça da mamãe é cool! Veja como usar o mom jeans, moda forte nos anos 80 e 90. Purepeople, Nova York, 17 mar. 2018. Beleza \& estilo. Disponível em: https://www.purepeople.com.br/noticia/mom-jeansveja-como-usar-e-onde-comprar-o-modelo-de-sucesso-dos-anos-80-e-90_ a219649/1. Acesso em: 25 jun. 2019.

18. OLIVEIRA, Aline Hilsendeger Pereira de. Responsabilidade socioambiental e APL inovativo na indústria da confecção de Santa Catarina. Curitiba: Appris, 2015.

19. OLIVEIRA, Gilberto José. Jeans, a alquimia da moda. Vitória: Edição independente, 2008.

20. PEZZOLO, Dinah Bueno. Moda fácil. São Paulo: Códex, 2003.

21. SGS. A SGS de forma resumida. Disponível em: https://www.sgsgroup.com. br/pt-br/our-company/about-sgs/sgs-in-brief. Acesso em: 25 jun. 2019.

22. SILVA, Vanessa Patrício da. Identificação de tecidos que laceiam, para evitar problemas com o consumidor final. 2014. Monografia (Especialização em Modelagem do Vestuário) - Universidade do Extremo Sul de Santa Catarina, Criciúma, 2014. Disponível em: http://repositorio.unesc.net/ bitstream/1/2505/1/Vanessa\%20Patricio\%20da\%20Silva.pdf. Acesso em: 2 jul. 2019.

23. YIN, Robert K. Estudo de caso: planejamento e métodos. 3. ed. Porto Alegre: Bookman, 2005.

24. ZDHC. About. About Us. What we do. Disponível em: https://www. roadmaptozero.com/about/. Acesso em: 25 jun. 2019. 